\title{
A study on epidemiological factors associated with anaemia in pregnancy
}

\author{
Sridhar $\mathbf{D}^{1}$, Sangeetha Jairaj ${ }^{2 *}$ \\ ${ }^{1}$ Assistant Professor, ${ }^{2}$ Associate Professor, Dept. of Community Medicine, ${ }^{\mathbf{1}}$ Gandhi Medical College, Secundrerabad, Telangana, \\ ${ }^{2}$ Government Medical College, Nalgonda, Telangana, India \\ *Corresponding Author: Sangeetha Jairaj \\ Email: sangeetargajula@gmail.com
}

\begin{abstract}
Introduction: Anaemia during pregnancy is one of the important factors associated with a number of maternal and foetal complications. It decreases the woman's reserve to tolerate bleeding either during or after child birth and makes prone to infections. Anaemia during pregnancy also has been associated with increased risk of intra uterine growth restriction, premature deli very, low birth weight (LBW) and maternal and child mortality. World Health Organization (WHO)/World Health Statistics data shows that 40.1\% of pregnant women worldwide were anaemic in 2016. The condition is prominent in Southeast Asian countries where about half of all global maternal deaths are due to anaemia and India contributes to about $80 \%$ of the maternal death due to anaemia in South Asia. There is marginally decrease in prevalence of anaemia in pregnant women in India from 58\% in NFHS-3 (National Family Health Survey-2005-06) to 50\% in NFHS-4 survey (2015-16).

Material and Methods: 1): To assess the prevalence of anaemia in pregnancy. 2): To determine association between social factors and anaemia in pregnancy. All pregnant women attending to OPD of ESIC hospital Hyderabad were considered for study. About 400 pregnant women include after obtaining oral consent. Women who don't have valid document about their Haemoglobin were not considered for study.

Results: Overall prevalence of anaemia among pregnant women was found $72.75 \%$. In the present study majority (59.5\%) were in $20-30$ years age group followed by $(27.3 \%)$ below 20 years age group while only $(13.2 \%)$ were above 30 years of age. Among the total study population, almost all the religions were equally distributed, with slightly higher proportion (27\%) of Hindus, followed by Muslims (24.5\%) and Christians and other religion are equally distributed 24\%. Majority (67\%) of them were Illiterate. Literates were 33\%. Most $(67.5 \%)$ of the subjects belongs to lower socio economic status. Middle and high class together constitutes 32.5\%. Majority (64.8\%) of study subjects were married below 18 years of age. Early pregnancies (pregnancies in < 18yrs) were seen in about $61.8 \%$ of the population. Conclusion: Anaemia among pregnant mothers is still highly prevalent in India. Majority physical, socio-demographic and cultural factors contributing for higher incidence.
\end{abstract}

Keyword: Anaemia, Pregnancy, Epidemiological factors.

\section{Introduction}

Anaemia during pregnancy is one of the important factors associated with a number of maternal and foetal complications. It decreases the woman's reserve to tolerate bleeding either during or after child birth and makes prone to infections. Anaemia during pregnancy also has been associated with increased risk of intra uterine growth restriction, premature delivery, low birth weight (LBW) and maternal and child mortality. ${ }^{1}$

World Health Organization (WHO)/World Health Statistics data shows that $40.1 \%$ of pregnant women worldwide were anemic in 2016. The condition is prominent in Southeast Asian countries where about half of all global maternal deaths are due to anemia and India contributes to about $80 \%$ of the maternal death due to anaemia in South Asia. There is marginally decrease in prevalence of anemia in pregnant women in India from 58\% in NFHS-3 (National Family Health Survey-2005-06) to $50 \%$ in NFHS-4 survey $(2015-16)^{2}$

Among the various causes of anaemia in women, iron deficiency is the most common cause, primarily due to their recurrent menstrual loss and secondary due to poor supply of iron in the diet. During pregnancy anemia is common due to increased demand of iron for the growing fetus and placenta; and increased red blood cell mass (with expanded maternal blood volume in the third trimester), which is further aggravated with other factors such as childbearing at an early age, repeated pregnancies, short intervals between pregnancies and poor access to antenatal care and supplementation. Indian Council of Medical Research considers haemoglobin $(\mathrm{Hb})$ level below $10.9 \mathrm{~g} / \mathrm{dl}$ as cutoff point for anemia during pregnancy. ${ }^{1}$

The Ministry of Health and Family Welfare, Government of India has given emphasis to prevent anaemia under RMNCH+A services. National Health Policy 2017 also addressed malnutrition and micronutrient deficiencies interventions. "National Iron Plus Initiative" launched in 2013 is a comprehensive strategy to combat the public health challenge of iron deficiency anaemia (IDA) prevalent across the life cycle.

National Nutrition Mission has been setup under the oversight of the Ministry of Women and Child Development with the aim to reduce anaemia among young children, adolescent girls and women of reproductive age (15-49 years) by one third of NFHS-4 levels by $2022 .^{2}$

\section{Material and Methods Objectives}

1. To assess the prevalence of anaemia in pregnancy

2. To determine association between social factors and anaemia in pregnancy

All pregnant women attending to OPD of ESIC hospital Hyderabad were considered for study. About 400 pregnant women include after obtaining oral consent. Women who 
don't have valid document about their Haemoglobin were not considered for study.

Women were selected randomly. Data was analysed by using SPSS version 16 software. Binary logistic regression done to estimate likelihood ratio and odds ratio.

\section{Results}

Overall prevalence of anaemia among pregnant women was found $72.75 \%$.

In the present study majority $(59.5 \%)$ were in $20-30$ years age group followed by $(27.3 \%)$ below 20 years age group while only (13.2\%) were above 30 years of age.

Among the total study population, almost all the religions were equally distributed, with slightly higher proportion (27\%) of Hindus, followed by Muslims (24.5\%) and Christians and other religion are equally distributed $24 \%$.

Majority (67\%) of them were Illiterate. Literates were $33 \%$. Most $(67.5 \%)$ of the subjects belongs to lower socio economic status. Middle and high class together constitutes $32.5 \%$. Majority $(64.8 \%)$ of study subjects were married below 18 years of age. Early pregnancies (pregnancies in < $18 \mathrm{yrs})$ were seen in about $61.8 \%$ of the population.

Less birth spacing i,e $<2$ yrs was observed among $62.5 \%$ pregnant mothers. About $65 \%$ of the study population were having more than 3 members in the house and only $35 \%$ were having less than 3 members in their family. Only $6.8 \%$ of the study population were suffering from some kind of chronic illness. Worm infection was present in about $62.5 \%$ of the study population. Among the pregnant mothers, about $32.2 \%$ of them were having low pre pregnancy weight.

It was observed that the proportion of anaemia was equally distributed among all religions association between and religion was not found to be significant statistically. $(\mathrm{p}=0.29)$
The proportion of anaemia was significantly high among illiterates i.e 78.4\% when compared to those who were literate i.e $58.3 \% \quad(\mathrm{p}<0.001)$.Higher proportion of anaemia was observed among those who belonged to lower socioeconomic status $(80.4 \%)$ when compared to those who belong to higher (middle and high) socioeconomic status $(53.8 \%)$. This association was found to be statistically significant $(\mathrm{p}<0.001)$. It was observed that the proportion of anaemia was high (77.6\%) among those who got married before 18 years of age when compared to those who got married after 18 years $(61 \%)$. This association was found to be statistically significant $(\mathrm{p}=0.001)$.The proportion of anaemia was found to be significantly high $(80.2 \%)$ among the study subjects who got pregnant before 18 years of age when compared to those who got pregnant after 18 years of age $(58.2 \%)(\mathrm{p}<0.001)$.Significantly higher proportion of anaemia was present among the study subjects who maintained a minimum gap of 2 years in between two successive pregnancies i.e $78.4 \%$ when compared to those who don't maintain i.e $60.7 \%(\mathrm{p}<0.001)$.Higher proportion of anaemia was observed among the study subjects who belong to household with more no. of persons i.e $>3$ persons (75.4\%) when compared to those who belong to household with less no. of persons i.e $\leq 3$ persons $(65 \%)$. This association was found to be statistically significant $\mathrm{p}<0.05)$. It was observed that the proportion of anaemia was high among those who were suffering from chronic illness (73.5\%) when compared to those who were not suffering from it $(68.7 \%)$. But this association was not found to be significant statistically $(p=0.3)$. The proportion of anaemia was found to be significantly high among the study subjects who had worm infestations i.e $76.8 \%$ when compared to those who don't have worm infestations i.e $63.3 \%(p<0.01)$. It was observed that the proportion of anaemia was high among the study subjects whose pre pregnant weight was low $(82.7 \%)$ when compared to those whose pre pregnant weight was normal $(48.4 \%)$ and was found to be statistically significant $(\mathrm{p}<0.001)$. (Table 1$)$

Table 1: Association of anaemia with various epidemiological variables

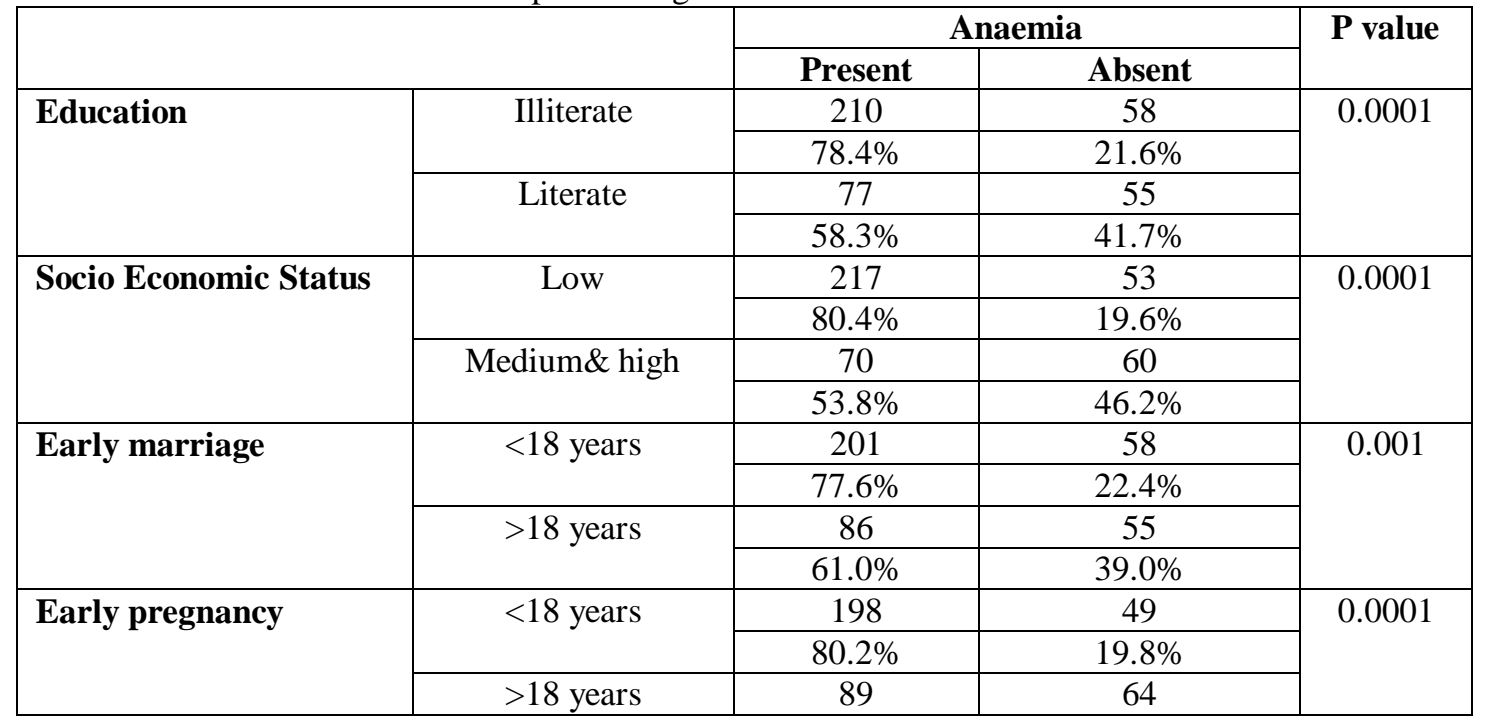




\begin{tabular}{|c|c|c|c|c|}
\hline & & $58.2 \%$ & $41.8 \%$ & \\
\hline \multirow[t]{4}{*}{ Birth spacing } & \multirow[t]{2}{*}{$<2$ years } & 196 & 54 & \multirow[t]{4}{*}{0.0001} \\
\hline & & $78.4 \%$ & $21.6 \%$ & \\
\hline & \multirow[t]{2}{*}{$>2$ years } & 91 & 59 & \\
\hline & & $60.7 \%$ & $39.3 \%$ & \\
\hline \multirow{4}{*}{$\begin{array}{l}\text { No. of persons in the } \\
\text { home }\end{array}$} & \multirow[t]{2}{*}{$>3$ members } & 91 & 49 & \multirow[t]{4}{*}{0.028} \\
\hline & & $65.0 \%$ & $35.0 \%$ & \\
\hline & \multirow[t]{2}{*}{$<3$ members } & 196 & 64 & \\
\hline & & $75.4 \%$ & $24.6 \%$ & \\
\hline \multirow[t]{4}{*}{ Chronic illness } & \multirow[t]{2}{*}{ Present } & 186 & 67 & \multirow[t]{4}{*}{0.303} \\
\hline & & $73.5 \%$ & $26.5 \%$ & \\
\hline & \multirow[t]{2}{*}{ Absent } & 101 & 46 & \\
\hline & & $68.7 \%$ & $31.3 \%$ & \\
\hline \multirow[t]{4}{*}{ Worm infection } & \multirow[t]{2}{*}{ Present } & 192 & 58 & \multirow[t]{4}{*}{0.004} \\
\hline & & $76.8 \%$ & $23.2 \%$ & \\
\hline & \multirow[t]{2}{*}{ Absent } & 95 & 55 & \\
\hline & & $63.3 \%$ & $36.7 \%$ & \\
\hline \multirow[t]{4}{*}{ Pre pregnancy weight } & \multirow[t]{2}{*}{ low } & 225 & 47 & \multirow[t]{4}{*}{0.0001} \\
\hline & & $82.7 \%$ & $17.3 \%$ & \\
\hline & \multirow[t]{2}{*}{ Norma } & 62 & 66 & \\
\hline & & $48.4 \%$ & $51.6 \%$ & \\
\hline
\end{tabular}

Lower Education, Low SES, Early Marriage, Early Pregnancy, Birth Spacing <2 years, Worm Infection, Low Pre pregnancy weight are the predictive significant epidemiological variables for anaemia. (Table 2)

Table 2: Bi-variate logistic regression analysis

\begin{tabular}{|l|c|c|c|c|}
\hline & B & Sig. & Odds ratio & 95\% CI \\
\hline Education & 1.033 & 0.0001 & 2.810 & $1.636-4.824$ \\
\hline Socio Economic Status & 0.876 & 0.001 & 2.400 & $1.411-4.083$ \\
\hline Early marriage & 0.621 & 0.026 & 1.862 & $1.075-3.223$ \\
\hline Early pregnancy & 0.768 & 0.005 & 2.155 & $1.254-3.704$ \\
\hline Birth spacing & 0.836 & 0.002 & 2.307 & $1.362-3.908$ \\
\hline No. of persons in the home & -0.289 & 0.295 & 0.749 & $0.436-1.286$ \\
\hline Worm infection & 0.584 & 0.029 & 1.794 & $1.062-3.03$ \\
\hline Pre pregnancy weight & 1.619 & 0.0001 & 5.048 & $2.968-8.587$ \\
\hline
\end{tabular}

\section{Discussion}

Overall prevalence of anaemia among pregnant women was found $72.75 \%$ in the present study. Samuel et al. In a similar study which was done at an urban public health facility in Bangalore observed lesser prevalence rate of $30.3 \% .^{3}$ prevalence rate of $23.16 \%$ observed in Vellore $^{4}$ and prevalence rate of $50.1 \% \mathrm{t}$ was found in urban Udupi. ${ }^{5}$ but higher prevalence rate among urban women found in Viveki et al., Totega, Agarwal et al., and Gautam et al. (82.9\%, $84.9 \%, 84 \%$, and $96.5 \%$, respectively). ${ }^{6-9}$

This disparity could be attributed to a plethora of factors such as variation in the socio-demo graphic characteristics, ESIC hospital servers diverse vast people where they posses different cultures, social behaviour etc. More than $70 \%$ of the women in our study were Muslims. Other studies have found a much higher morbidity because of anemia in this subpopulation owing to various reasons such as poor socio-economic status and overcrowding. ${ }^{10}$

Religious association not found it is similar with study conducted by Kumar V et al. ${ }^{11}$ But Lokare PO et al in
Aurangabad city did not observe any significant association in their study. ${ }^{12}$ In the present study we found that anaemia had a significant inverse association with educational attainment of the women. Similar significant association was also seen in other studies conducted by Lokare PO et al in Aurangabad city and Ansuman Panigrahi et al in Bhubaneswar ${ }^{12,13}$ whereas kumar $\mathrm{V}$ et al did not found any significant association between anaemia and educational status of the women. ${ }^{11}$ But in contrast with our study Mihiretie $\mathrm{H}$ et al reported significantly higher prevalence of anaemia among literates women than illiterates and kefiyalew $\mathrm{F}$ et al in south east Ethiopia also observed that anaemia was more common in literates $(32 \%)$ than illiterates $(25.3 \%) .^{14,15}$ In our study, the association of anaemia with socioeconomic classes was found to be statistically highly significant ( $\mathrm{p}=0.0066)$ and it come out to be important risk factor in development of anaemia in pregnancy. This might be due to availability and affordability of high-quality food with better socioeconomic status. Similar observation has been documented by other 
authors in their study. ${ }^{12,16,17}$ But Kumar $\mathrm{V}$ et al reported that association was not significant. ${ }^{11}$

It was observed in the present study that, among pregnant women with birth interval more than 3 years, anemia was high with an odds ratio 2 , in a similar study conducted by Alemayehu Bekele in Ethiopia birth interval was significantly associated with anemia with an odds ratio of $3 .^{18}$

There was a significant statistical association between anemia and complications during pregnancy in the present study, which is similar to the study conducted by Nair et al. ${ }^{19}$

\section{Conclusion}

Anaemia among pregnant mothers is still highly prevalent in India. Majority physical, socio-demographic and cultural factors contributing for higher incidence. Self care and appropriate utilization of health care delivery will helps to decrease the prevalence. Cultural and demographic factors can be addressed through legislations and health education.

\section{Source of Funding}

None.

\section{Conflict of Interest}

None.

\section{References}

1. WHO/CDC. Worldwide prevalence of anaemia 1993-2005. WHO Global Database on Anaemia. Geneva, World Health Organization, 2008 (http://whqlibdoc.who.int/publications/2008/9789241596657_e ng.pdf, accessed 1 November 2019).

2. MIHFW. India Fact Sheet National family health Survey 20152016(http://rchiips.org/NFHS/pdf/NFHS4/India.pdf. accessed on 3rd november 2019)

3. Samuel T, Thomas T, Finkelstein J, Bosch R, Rajendran R, Virtanen $\mathrm{S}$, et al. Correlates of anemia in pregnant urban South Indian women: A possible role of dietary intake of nutrients that inhibit iron absorption. Public Health Nutr. 2012;16:31624.

4. Madhu Priya N, Bijesh Y, Ruby J. Prevalence of anemia in pregnant women at booking visit in India. Indian J Obstet Gynecol Res. 2017;4(3):244-8.

5. Noronha J, Bhaduri A, Bhat H, Kamath A. Maternal risk factors and anemia in pregnancy: A prospective retrospective cohort study. J Obstet Gynecol. 2010;30:132-6.

6. Viveki RG, Halappanavar AB, Viveki PR, Halki SB, Maled VS. Prevalence of anaemia and its epidemiological determinants in pregnant women. Al Ameen J Med Sci. 2012;5:216-23.
7. Gautam VP, Bansal Y, Taneja DK, Saha R, Shah B, Marg Z, et al. Prevalence of anaemia amongst pregnant women and its socio-demographic associates in a rural area of Delhi. Indian $J$ Community Med. 2002;27(4):157-60.

8. Agarwal KN, Agarwal DK, Sharma A, Sharma K, Prasad K, Kalita MC, et al. Prevalence of anaemia in pregnant \& lactating women in India. Indian J Med Res. 2006;124:173-84.

9. Totega GS. Prevalence of anaemia among pregnant women and adolescent girls in 16 districts of India. Food Nut Bull. 2006;27:311-5

10. Bansal B, Takkar J, Kumaragarwal D, Agarwal S. Comparative study of prevalence of anemia in Muslim and non-Muslim pregnant women of western Rajasthan. Int J Res Health Sci. 2013;47-52.

11. Kumar V, Sunderam S, Haider S, Kashyap V. A study on status of anaemia in pregnant women attending urban health training centre, RIMS, Ranchi. Indian J Comm Health. 2014;26(Suppl S(2):112-7.

12. Lokare PO, Karanjekar VD, Gattani PL, Kulkarni AP. A study of prevalence of anemia and sociodemographic factors associated with anemia among pregnant women in Aurangabad city, India. Ann Nigerian Med. 2012;6:30-4.

13. Panigrahi A, Sahoo PB. Nutritional anemia and its epidemiological correlates among women of reproductive age in an urban slum of Bhubaneswar, Orissa. Indian J Public Health. 2011;55:317-20.

14. Mihiretie H, Fufa M, Mitiku A, Bacha C, Getahun D, Kejela M, et al. Magnitude of Anemia and Associated Factors among Pregnant Women Attending Antenatal Care in Nekemte Health Center, Nekemte, Ethiopia. J Med Microb Diagn. 2015;4(3). doi:10.4172/21610703.1000197.

15. Kefiyalew F, Zemene E, Asres Y, Gedefaw L. Anemia among pregnant women in Southeast Ethiopia: prevalence, severity and associated risk factors. BMC Res Notes. 2014,7:771.

16. Arlappa N, Meshram II, Balakrishna N, Harikumar R, Rao KM, Laxmaiah A. Prevalence of anaemia among different physiological groups in the rural areas of Maharashtra. Ind $J$ Comm Health. 2014;26(3):278-84.

17. Bentley ME, Griffiths PL. The burden of anemia among women in India. Eur J Clin Nutr. 2003;57:52-60.

18. Bekele A, Tilahun M, Mekuria A. Prevalence of anemia and its associated factors among pregnant women attending antenatal care in health institutions of Arba Minch town, Gamo Gofa Zone, Ethiopia: A Cross-sectional study. Anemia. 2016;2016:1073192.

19. Nair M, Choudhury MK, Choudhury SS, Kakoty SD, Sarma UC, Webster P, et al. Association between maternal anaemia and pregnancy outcomes: A cohort study in Assam, India. BMJ Glob Health. 2016;1:e000026.

How to cite this article: Sridhar D, Jairaj S. A study on epidemiological factors associated with anaemia in pregnancy. Indian $J$ Forensic Community Med. 2020;7(1):11-4. 